\title{
PROFESOR ÁLVARO VARGAS
}

\section{CDP: Profesor, por favor cuéntenos acerca de su formación y trayectoria académicas.}

Prof. Álvaro Vargas: Mi carrera docente comenzó en el año de 1979, cuando, desempeñándome como Fiscal del Juzgado Octavo Superior de Medellín, acepté la invitación del Profesor Alfonso Ortiz Rodríguez a impartir un curso de Derecho Procesal Penal en la Facultad de Derecho de la Universidad de Medellín, institución ésta donde -unos cuantos años atrás- me había recibido como Doctor en Derecho. A partir de ese momento (yo diría que por puro azar), he tenido, pues, que habérmelas, en forma simultánea, tanto con el Derecho Penal, en cuanto escenario de mi práctica profesional, como con el Derecho Procesal Penal, área ésta dentro de la cual se produjo mi primer acercamiento al mundo académico.

Con el paso de los años, al cultivo de estas dos disciplinas se fueron agregando, tanto el de la Teoría General de la Prueba (al principio como respuesta a las demandas propias del ejercicio profesional), como el de la Teoría General del Proceso (fruto de un concienzudo esfuerzo por explorar cada vez más el universo de lo procesal), al punto de que, en el año de 1996, la Facultad de Derecho de la Universidad Pontificia Bolivariana de Medellín (a cuya nómina profesoral me había integrado desde hacía varios años) tuvo a bien certificarme como Especialista en Derecho Procesal.

Para entonces, ya mi ciclo docente con la Universidad de Medellín (de cuya Facultad de Derecho había llegado a ser decano en el año de 1988), había concluido por mi propia voluntad, pero -casi al unísono- me habían abierto generosamente sus puertas (jsin yo haberlas tocado jamás!) las facultades de derecho de las Universidades Autónoma Latinoamericana (donde impartí lecciones de Teoría General del Proceso entre los años de 1987 y 1991) y Pontificia Bolivariana de Medellín, cuyos requerimientos apuntaban en la línea del Derecho Procesal Penal.

A esta última casa de estudios estuve ininterrumpidamente vinculado entre los años de 1988 y 2001, cuando, tras más de 20 años de intensa actividad académica (que -además de los cursos de pregrado y de la publicación de libros y artículos en revistas especializadas- incluía la participación en programas de posgrado de diferentes universidades y la intervención como ponente en distintos congresos y seminarios de carácter nacional e internacional), decidí liberarme, por algún tiempo, de las gratas pero extenuantes obligaciones docentes, para dedicarme por completo al ejercicio de mi profesión en el área penal. 
No había, empero, transcurrido siquiera un par de años desde mi retiro de los claustros universitarios, cuando, desde el Instituto de Ciencias de la Salud de Medellín (hoy Universidad Ces), se me invitó poner en marcha, como decano fundador, un nuevo programa de derecho, dejándoseme en plena libertad para implementar las estrategias formativas que me aconsejara mi experiencia y otorgándoseme la posibilidad de disponer (sin mayores estrecheces) de los recursos necesarios para ello.

Entre finales de 2003 y comienzos de 2009, comprometí, entonces, buena parte de mi energía vital (aunque sin abandonar del todo mi oficina de abogado) en el diseño e implementación del aludido proyecto, cuya suerte acompañé hasta cuando tuve la fortuna de graduar a los primeros egresados del programa, momento a partir del cual opté por retomar de lleno el ejercicio profesional, sin perjuicio de continuar adelantando (hasta culminar exitosamente las asignaturas que integraban el programa) los estudios de Filosofía que -a nivel de Doctorado- había comenzado a realizar en la Universidad Pontificia Bolivariana, poco tiempo después de haber aceptado el reto de poner en marcha la Facultad de Derecho de la Universidad Ces.

A propósito de la Filosofía, quisiera agregar, antes de proseguir, que, aunque yo no creo que exista ninguna relación especial entre ella y el derecho penal, de lo que sí no dudo es que el hábito de frecuentar los discursos que se producen en dicho ámbito contribuye en ingente medida a refinar los propios, al tiempo que ayuda a entender cómo casi todo en cualquier campo del saber puede ser controvertido.

Esclarecido lo anterior y tornando al relato atrás interrumpido, ocurrió, empero, que, casi en forma simultánea con mi voluntario retiro de la plurimentada decanatura, se me hizo desde la -hoy llamada- Escuela de Derecho y Ciencias Políticas de la Universidad Pontificia Bolivariana un amistoso llamado que me hizo retornar a ese claustro, donde, para cerrar mi dilatada carrera como docente de pregrado, entre los años de 2009 y 2011, además de tomar a mi cargo sendos cursos de Derecho Procesal Penal y Pruebas Penales, pude proseguir el estudio y la enseñanza (ya iniciados desde mi reciente tránsito por la decanatura que anteriormente mencioné) de la Teoría General del Derecho, disciplina ésta que, conjuntamente con la Filosofía del Derecho, aglutina, desde hace varios años, el grueso de mis preocupaciones, disertaciones y publicaciones académicas.

CDP: Recordadas ya su formación y trayectoria académicas, descríbanos, de forma resumida, su trayectoria profesional y, en especial, algunos de los aspectos más relevantes de su carrera como abogado penalista en ejercicio.

Prof. Vargas: Después de un breve tránsito por la rama judicial y el Ministerio Público, que se extendió entre el primero de septiembre de 1975 y el once de enero de 1980 (lapso dentro del cual oficié, sucesivamente, como Juez Promiscuo Municipal de Montebello, Juez $28^{\circ}$ Penal Municipal de Medellín y Fiscal del Juzgado Octavo Superior de la misma ciudad), abrí formalmente -a partir de la segunda de las aludidas fechas- una oficina de abogado penalista que, desde entonces, no 
solo no ha cerrado nunca sus puertas, sino que, adicionalmente, me ha permitido proveer decorosamente a mi 'congrua subsistencia' (para decirlo a la manera del Código Civil) y a la de todas las personas a mi cargo.

Si hubiere que intentar un balance (como se me sugiere en la pregunta), yo señalaría que, al cabo de estos 36 años de vida dedicados al ejercicio profesional independiente en el área penal, puedo inventariar como inestimables activos intangibles, por un lado, la certeza de no haber defendido nunca, a mis ojos, una causa manifiestamente injusta y, por el otro, la de no haberlo hecho jamás utilizando métodos o procedimientos reñidos con el decoro propio de la profesión, hasta el punto de que todavía hoy (en un medio como el nuestro, donde nada se perdona ni se olvida) puedo caminar solo por cualquier parte, sin experimentar ningún temor.

CDP: ¿Quiere contarles a nuestros lectores cuál ha sido su mayor éxito profesional en este ámbito y cuál su mayor frustración?

Prof. Vargas: Más que hablar de un 'éxito profesional', en singular, me gustaría resaltar que, a esta altura de mi periplo profesional -que ya no puede considerarse breve-, creo poder enorgullecerme del afecto y la calidez con que suelo ser recibido en los despachos de los fiscales, jueces y magistrados que, a lo largo de todos estos años, han interactuado conmigo en el infatigable trasegar por los estrados judiciales.

Esos mismos funcionarios -debo resaltarlo-, agrupados en el Colegio de Jueces y Fiscales de Antioquia (el más antiguo e importante del país), me han honrado, incluso, en dos distintas oportunidades, con sendas condecoraciones: una, al mérito académico; otra (para mí, más importante, pues equivale a enlistarme entre sus pares), exaltándome a la calidad de miembro honorario de esa reputada institución.

En punto de 'frustraciones' (lo digo en plural aunque -en verdad- no han sido tantas), no puedo dejar de rotular como tales aquellas eventualidades en las cuales (tal vez por defecto de imaginación) no he logrado encontrar la vía argumental o el lenguaje adecuados para persuadir a un juzgador, singular o colegiado, de la necesidad de absolver a un justiciable.

\section{CDP: ¿Cuál es el teórico del derecho penal que más ha influido en su formación como académico y como cultor de las disciplinas jurídico-penales?}

Prof. Vargas: Como habrá ido quedando seguramente claro a lo largo de esta conversación, no obstante haber completado ya -con buen crédito y relativo éxito- más de 36 años de ejercicio como abogado penalista, yo no me atrevo a considerarme un 'cultor de las disciplinas jurídico-penales', por lo menos al mismo nivel en que lo soy (o lo he sido) del Derecho Procesal, tanto en lo relacionado con los macro-discursos propios de la Teoría General del Proceso y de la Teoría General de la Prueba, como en lo relativo a los discursos -un poco más específicos- del Derecho Procesal Penal y de las Pruebas Penales. 
Con todo, a pesar de que, tanto en la órbita del Derecho Penal como en la del Procesal, el grueso de la literatura al uso suele consistir en monografías, manuales o tratados, invariablemente escritos -salvo algunos textos alemanes- con fines didácticos (es decir, más para divulgar que para producir conocimiento), me gustaría hacer referencia a un par de obras salidas desde el mismo enclave geográfico, pero separadas entre sí por una distancia de 225 años, de cada una de las cuales puede decirse que sacudió y refrescó, en su momento, los fundamentos epistemológicos del discurso punitivo. Aludo, por un lado, al opúsculo 'De los delitos y la penas' de Beccaria y, por el otro, a esa especie de suma (en el sentido medieval) que, bajo el sugerente nombre de 'Teoría del garantismo', fuera desarrollada por Luigi Ferrajoli en su conocido libro 'Derecho y razón', cuyo tratamiento lúcido e integral de los distintos saberes constitutivos de (o relacionados con) el campo de lo punible, la convierte en una obra irrepetible e insular.

\section{CDP: ¿Cuál es el profesor que más influyó en su formación profesional y académica y por qué?}

Prof. Vargas: Tal vez con la sola excepción del polifacético abogado Federico Estrada Vélez (quien, aparte de connotado penalista y autor de un muy buen libro sobre dicha especialidad, llegó a ser, incluso, Senador de la República y Magistrado de la Sala Penal de la Corte Suprema de Justicia), la facultad de Derecho de la Universidad Medellín no contaba, durante mi época de formación, con ninguna figura especialmente rutilante dentro de su planta de docentes, un buen número de los cuales estaba conformado, en efecto, por abogados en ejercicio, jueces, fiscales o magistrados con adecuada solvencia en lo profesional y aceptable competencia en lo académico.

Entre ellos, al lado de los profesores -para entonces, todavía jóvenes- Juan Fernández Carrasquilla y Guillermo Duque Ruiz, quienes, con el correr del tiempo, terminarían por forjarse una merecida reputación en el campo penal (el primero, como reconocido tratadista y el segundo, gracias a sus ejecutorias como Magistrado de la Sala de Casación Penal de la Corte Suprema de Justicia), no puedo, empero, dejar de mencionar al Profesor Alfonso Ortiz Rodríguez (para la época, Magistrado de la Sala Penal del Tribunal Superior de Medellín), poseedor de una vasta y miscelánea cultura no circunscrita al mero ámbito del Derecho, quien me enseñó -con su ejemplo- que, para poder hablar de determinadas cosas, no solo se necesita conocimiento, sino, también, un cierto desenfado capaz de poner al descubierto cuánta trivialidad subyace bajo algunos temas aparentemente dotados de trascendencia.

CDP: Al hablar de su obra académica, queremos preguntarle por un trabajo en particular: La Fiscalía General de la Nación desde el 'Sueño Mariposa'. Por favor cuéntele a los lectores qué lo llevó a publicar, entre los años de 1997 y 1998, ese libro. 
Prof. Vargas: Por salud mental, yo no suelo releer nada de lo que escribo, salvo que exista para ello algún motivo especial, ni acostumbro hacerle seguimiento después de haberme desvinculado de él- a ningún proyecto académico que haya tenido a mi cargo. Por ello, si bien tengo muy claro el talante con el cual me apliqué a componer, en su momento, ese entrañable texto, no me es fácil evocar ahora, después de más de tres lustros de haberlo escrito, cuál fue el pretexto de que me valí para encubrir (si fue que lo hice) las pulsiones propias de la vanidad, que -como todos sabemos- son el verdadero y único acicate de quien escribe siquiera una página sin tener ninguna necesidad de hacerlo.

Lo que sí quiero destacar es que, sin haber sido propiamente un best seller (como sí lo fue, por ejemplo, la primera edición de la Estructura básica del proceso penal colombiano), esa es una obra que en modo alguno me deshonra, pues -no obstante haber sido compuesta a medio camino entre la crónica y el ensayo, para dar cuenta de un determinado estado de cosas en una específica e irrepetible coyuntura- posee un tono y una escritura tan desenfadados y desenvueltos, que, una vez comenzada su lectura, no le queda al lector opción distinta a la de terminarla, como tuvo a bien hacérmelo saber, en su momento, el recordado Profesor (y exquisito hombre de letras) Carlos Gaviria Díaz.

\section{CDP: ¿Qué opina Usted del estado actual de la dogmática penal en el conti- nente latinoamericano $y$, en particular, en Colombia?}

Prof. Vargas: En Latinoamérica o en cualquier parte (pues en este campo no creo que la Geografía haga mucha diferencia), la dogmática penal ha tenido y tendrá sentido, siempre y cuando -fiel a la conocida lección del Profesor Gimbernat Ordeig-sirva tanto para racionalizar como para hacer previsible e igualitaria, sustrayéndola al capricho y a la arbitrariedad judicial, la aplicación, en concreto, del derecho penal.

Alejada de ese cometido esencialmente práctico y convertida en exótico pasatiempo de un número cada vez más reducido de especialistas, es claro que la dogmática terminará perdiendo todo contacto con el mundo -dramáticamente terrenal- de lo forense. Otro tanto le acontecerá, por supuesto, si, sucumbiendo a los cantos de sirena que ha venido entonando cierto pensamiento políticamente autoritario, continúa empecinada en colocar en el lugar otrora reservado a los seres humanos a unos meros portadores de roles, cuya condición de infractores de la ley penal no dimana, en absoluto, de la efectiva lesión o puesta en peligro de determinados bienes jurídicos, sino del hecho de haber defraudado las expectativas inherentes a su respectivo rol.

CDP: Como profesor universitario se ha granjeado siempre el afecto y la admiración de sus estudiantes, ¿qué consejos les daría a los jóvenes profesores que se dedican a la enseñanza del derecho penal? 
Prof. Vargas: Que asuman cada clase como si fuera la primera o la última que van a impartir. Que entiendan que ningún auditorio, grande o pequeño, tiene existencia como tal antes de que el expositor lo construya. Por ello, es deber de quien asume el reto de hablar en público cerciorarse de que cada uno de los integrantes del grupo al cual se dirige (si es pequeño) o la gran mayoría de los mismos (si es grande) se conecte con su discurso, manteniendo, al efecto, permanente contacto visual con todos -en general-, pero con ninguno -en particular-, sin omitir interpelarlos de vez en cuando, procurando, en esos casos, llamar al interpelado por su nombre.

De todas maneras, quien decida plantarse ante un auditorio (ya construido o por construir) no puede olvidar que, al ex-poner (es decir, al poner afuera lo que tiene adentro), simultáneamente, se expone. De ahí que quien no tenga nada que ex-poner, es mejor que no (se) exponga.

Obviamente, todos estos consejos (y recuérdese que, alcanzadas ciertas cotas existenciales, lo mejor que hacemos los mayores es aconsejar) suponen la pervivencia de aquella relación vertical dentro de la cual interactuaba, en los comienzos de mi carrera docente, el binomio profesor/alumno, que, luego de haber sido reemplazado -en la jerga de la burocracia universitaria- por el binomio docente/ discente, hoy prácticamente ya no existe, pues, en el marco de una educación entendida como proceso, ya no hay profesores sino 'facilitadores' de dicho proceso, respecto del cual tampoco hay alumnos sino 'participantes'.

CDP: Atendido el contexto que propone la llamada 'sociedad de la información' y el uso extendido de las nuevas tecnologías connatural a la misma, ¿cuál cree Usted que es su impacto en la enseñanza del Derecho penal?

Prof. Vargas: En un entorno social caracterizado, cada vez más, por la proliferación de aquellos contactos inexistentes (o 'no-contactos'), que suelen suscitarse dentro de los 'no-lugares' de que habla la antropología urbana contemporánea (aeropuertos, centros comerciales, etc.), no es extrañar el hecho de que, cada vez con más ímpetu, los administradores oficiales del saber propugnen por erigir al 'aula virtual' como el escenario más adecuado para el desenvolvimiento del proceso enseñanza/aprendizaje.

Cuando esa tendencia se consolide, yo no creo que se pueda seguir hablando (al menos en el sentido en que hoy lo hacemos) de 'enseñanza del Derecho penal', pues, a diferencia de lo que actualmente ocurre en el aula convencional, en el irreal ciberespacio 'ocupado' por el 'aula virtual', si bien hay confluencia de discursos, hay una sobrecogedora ausencia de personas, que convierte en un empeño vano (por no decir ridículo), la pretensión de hablar de derecho y, más aún, de derecho penal.

No obstante, ante la otrora impensable posibilidad de acceder a gigantescas bases de datos automáticamente desplegadas ante nuestros ojos por obra de un sencillo click, es indudable que la utilización de las nuevas tecnologías ha permitido la 
toma de contacto con repertorios jurisprudenciales y publicaciones especializadas en distintos idiomas, cuyo obligatorio manejo ha tornado innegablemente más exigente la actividad académica para todos los involucrados en ella.

CDP: El sistema procesal penal de tendencia acusatoria introducido por la Ley 906 de 2004 y su ulterior puesta en funcionamiento han suscitado muchas críticas desde diversos sectores. A partir de su experiencia como abogado penalista en ejercicio y teórico en estas materias, díganos cuál es su percepción sobre el tema y, en caso de estimarlos necesarios, qué cambios le haría al modelo procesal penal actual.

Prof. Vargas: Después de los frenéticos mandobles que -desde los poderes legislativo, ejecutivo y judicial- han venido propinándosele a ese desfalleciente modelo procesal, durante la última década, yo diría que, por sustracción de materia, cada vez va quedando menos que modificarle a un sistema de juzgamiento cuyo certificado de defunción acaba tal vez de ser expedido por la Sala de Casación Penal de la Corte Suprema de Justicia, cuando, mediante sentencia de casación de fecha 25 de mayo de 2016 (radicación No. 43837), optó por reconocerle al juez de conocimiento la potestad de condenar al acusado, en contravía de una solicitud de absolución emanada de la fiscalía.

Semejante prerrogativa en nada se aviene, por supuesto (como la propia Corte en su sentencia lo reconoce), con la condición de tercero imparcial que se predica del juez en los sistemas de estirpe acusatoria, pero compagina a cabalidad con el 'juez que todo lo puede', cuyo linaje inquisitivo parece empeñada en rehabilitar una cierta corriente de opinión manifiestamente afín a la ideología neo-constitucional.

Con todo, si de pensar en términos de reformas se trata, yo sugeriría examinar con detenimiento, aparte de lo relacionado con la procedencia de las medidas cautelares privativas de la libertad (obviamente, para reducir al mínimo político-criminalmente tolerable su viabilidad), temas como el de la pervivencia o no -y en qué condiciones- de la audiencia de formulación imputación (tópico respecto del cual la solución simplista de eliminarla me parece jurídicamente discutible), o el de someter la admisibilidad formal y material de la acusación -como prerrequisito del juicio- al control de un juez del mismo rango y especialidad del de conocimiento, aunque distinto, como es lógico, de este último.

Sin embargo, más que ajustes referidos a una u otra institución, lo que realmente urge hacer respecto de un modelo procesal que -como el de la Ley 906 de 2004- se halla edificado sobre la base de una investigación técnica y eficaz (dirigida y coordinada por un fiscal adecuadamente respaldado por un número suficiente de idóneos investigadores de campo y de laboratorio), es dotarlo de los recursos humanos y económicos necesarios para que pueda operar en las condiciones en que fue concebido, incrementando significativamente la planta de fiscales e investigadores llamados a adelantar, dentro de los plazos legalmente establecidos, las 
investigaciones al término de las cuales puedan ser efectivamente acusados ante los jueces, cuando a ello haya lugar, los presuntos infractores de la ley penal.

Naturalmente, nada de cuanto viene de ser dicho tendrá sentido si, paralelamente, no comienza a desandarse, cuanto antes, el deletéreo camino que, bajo la equivocada consigna de derrotar a cualquier precio a la delincuencia organizada (como si esa fuera una tarea de los jueces y no de los organismos de seguridad del Estado), ha terminado por arrastrar a todos los protagonistas del proceso penal hacia aquel insondable despeñadero ético que se nombra con la expresión 'justicia premial', donde la delación, el soborno, el chantaje y, en general, todos los métodos de común usanza en el mundo del hampa, han terminado siendo aceptados, recompensados e incluso estimulados en (y desde) los estrados judiciales.

CDP: ¿Qué opina del estado actual de la administración de justicia en Colombia? ¿Cómo cree que podría mejorar?

Prof. Vargas: Entendiendo la 'administración de justicia' (escrita, obviamente, con ' $j$ ' minúscula) como aquella actividad burocrática consistente en aplicar o hacer actuar el derecho penal material en los casos concretos, yo creo que, al margen de cualquier reforma centrada en el proceso o en el procedimiento (del estilo de las señaladas en la respuesta anterior), es urgente pensar seriamente en el modelo de juez que se hace necesario implementar, porque si en algo ha habido improvisación, con ocasión del cambio de método de juzgamiento, ha sido, precisamente, en ese aspecto.

De veras, tratándose -como se trata- de un modelo procesal dentro del cual la actuación debe surtirse preponderantemente en audiencias, sin margen de error puede afirmarse que el adecuado funcionamiento del mismo reclama de los jueces unas destrezas y unas competencias completamente distintas de las que les exigía el método escritural propio del sistema tendencialmente inquisitivo, que -desde tiempos inmemoriales- había sido el escenario del quehacer funcional de aquéllos.

Sometidos sus actos, en efecto -como consecuencia del principio de publicidad-, al permanente escrutinio de la comunidad y forzados, por ende, a resolver cualquier incidente, solicitud o controversia, no propiamente en la intimidad de sus despachos, sino a la vista de todo el mundo y en el ambiente no pocas veces caldeado de la audiencia, todo indica que, de acuerdo con el modelo procesal vigente y sin olvidar las consabidas exigencias de honestidad e imparcialidad, los principales atributos de los jueces deberían ser, en lo personal, una adecuada madurez existencial; en lo psicológico, un inalterable equilibrio emocional, y, en lo profesional, una apropiada formación jurídica, debidamente avalada por una trayectoria suficientemente amplia.

Desafortunadamente, salvo en lo relacionado con la instrucción jurídica (que no puede confundirse con la 'formación' en dicho campo), es muy poco, en realidad, lo que las facultades de derecho pueden aportar al proceso formativo de los jueces, que -en la práctica- suele tomar muchísimos años, pues, como bien lo 
reconocen quienes han enaltecido tan honrosos cargos, juzgar es algo que los jueces van aprendiendo a hacer con el tiempo. Es por eso que resulta tan curioso el hecho de que, cuando ya los jueces han alcanzado los conocimientos, la madurez, el equilibrio y la experiencia necesarios para encarar con la debida competencia la tarea de juzgar, simultáneamente se procede a excluirlos de la carrera judicial, bajo el pretexto de que han alcanzado ya la 'edad de retiro forzoso', que, en el insólito caso colombiano, es de 65 años.

Como corolario de lo anterior, ninguna duda puede haber, entonces, en el sentido de que, de cara al modelo procesal actualmente vigente entre nosotros, la opción de ser ungido como juez penal, de cualquier categoría, no puede ser para ningún abogado el punto de partida sino el punto de llegada de una impecable carrera profesional. En esta dirección, se me antoja inaplazable la adopción de medidas enderezadas a procurar que, en la práctica, ello comience a ser así.

Para cerrar esta dilatada respuesta (centrada, por razones obvias, en la figura del juez profesional), no quisiera dejar de hacer una breve referencia a los jueces legos, cuya eventual intervención en el proceso penal colombiano, además de hallarse constitucionalmente prevista, me atrevo a calificar, incluso, como francamente deseable, no solo porque el innegable espíritu democrático que la inspira le confiere una elevada dosis de legitimidad, sino porque, al involucrar a la comunidad en un asunto que realmente le interesa (porque la afecta), termina refrescando y aireando una tarea que, en manos de los jueces profesionales, no deja de exhibir, a veces, un cierto componente de rutina.

\section{CDP: ¿Cómo ve la academia actual? ¿Cuál cree que es el futuro de la misma?}

Prof. Vargas: Como es de sobra conocido, atendido el actual funcionamiento de las leyes de la oferta y la demanda en el mundo académico, desde la burocracia universitaria se ha venido exigiendo cada vez más la exhibición, por parte de los aspirantes a profesores en el campo del derecho, de plurales y sucesivos títulos de posgrado, cuya obtención suele traducirse para aquéllos en un desmesurado alargamiento de su etapa de escolarización, en detrimento, claro está, de casi todo contacto con la práctica profesional, que, en el caso de los abogados -sobre todo en el área penal-constituye un componente indispensable dentro de su formación.

Dentro del aludido contexto, nada de raro tiene, entonces, encontrar publicitados -y hasta acreditados- programas de derecho, donde, en contravía -incluso- del sentido común, algunas de las más formativas y exigentes asignaturas del currículo penal se hallan en manos de circunspectos doctores que nunca en su vida han acusado, defendido o juzgado a nadie y que muy posiblemente -cabe sospecharlo- ignoran hasta cómo se redacta un poder.

En beneficio de la academia, es claro que semejante estado de cosas tiene, inexorablemente, que cambiar, no propiamente para regresar a la época en que se accedía a la docencia con el mero título de pregrado (pues las condiciones impuestas por 'la mano invisible del mercado' hoy en día son otras), sino para 
que no se deje de exigir a los futuros profesores, al lado de una adecuada madurez existencial y de una trayectoria ética inobjetable, una óptima formación académica, complementada con una satisfactoria dosis de experiencia profesional en sus respectivos campos.

CDP: ¿Qué consejo le daría a quienes se inician o aspiran recorrer el camino del conocimiento jurídico-penal?

Prof. Vargas: Que si no tienen la creatividad y la imaginación propias del mundo del arte, el rigor y la coherencia argumental connaturales al campo de la filosofía y la presencia de ánimo necesaria para batallar con su propia desesperanza día tras día, por ningún motivo se atrevan a trasegar por ese camino. 